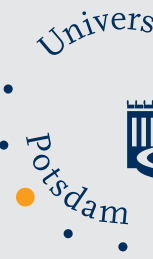

Gisbert Franselow | Matthias Schlesewsky | Ralf Vogel Thomas Weskott

\title{
Animacy effects on crossing wh-movement in German
}

Suggested citation referring to the original publication:

Linguistics 49(4) (2011), 657-683

DOI http://dx.doi.org/10.1515/LING.2011.021

Postprint archived at the Institutional Repository of the Potsdam University in:

Postprints der Universität Potsdam

Humanwissenschaftliche Reihe ; 299

ISSN 1866-8364

http://nbn-resolving.de/urn:nbn:de:kobv:517-opus4-93630 



\title{
Animacy effects on crossing wh-movement in German ${ }^{1}$
}

\author{
GISBERT FANSELOW, MATTHIAS SCHLESEWSKY, RALF VOGEL, \\ AND THOMAS WESKOTT
}

\begin{abstract}
This article presents several acceptability rating experiments concerned with crossing wh-movement in German multiple questions. Our results show that there is no general superiority effect in German, thus refuting claims to the contrary by Featherston (2005). However, acceptability is reduced when a whphrase crosses a wh-subject with which it agrees in animacy. We explain this finding in terms of the availability of different sorting keys for the answers to the multiple questions.
\end{abstract}

\section{Introduction}

Grammatical contrasts often yield only rather subtle differences in acceptability. This can lead to problems when such judgments figure in arguments for specific syntactic assumptions. Schütze (1996) exemplifies this difficulty in various domains, and argues that, in principle, it can be coped with by controlled acceptability rating experiments. A recent example with far-reaching theoretical consequences involves the discussion of wh-island constraints for in situ wh-phases in Japanese (Kitagawa and Fodor 2006; Ishihara 2005), where it could be shown that alleged subjacency effects on in situ wh-phrases do not exist. So-called "third-wh-effects" in English multiple questions also disappear under closer inspection (Clifton et al. 2006; Fedorenko and Gibson 2010).

This paper is concerned with multiple questions, too. The superiority condition (Chomsky 1973) rules out crossing wh-movement in English but apparently not in German, as the differing status of (1a) and (2a) illustrates. This contrast between English and German has served as the basis for important theoretical claims (e.g., Chomsky 2005; Haider 1981; Müller 2004; Pesetsky 2000), and many more attempts of accounting for this difference at a lower level can be found (Fanselow 2004; Haider 2004; Noonan 1988; Wiltschko 1998). 
(1) a. Who t said what?

b. *What did who say t?

(2) a. Wer sagte was?

who said what

(=1a)

b. Was sagte wer?

$(=1 \mathrm{~b})$

In the light of the attention which the absence of superiority effects in German has received, it came as a surprise that Featherston (2005) denied the existence of a categorical difference in the acceptability of (1b) and (2b). Featherston justified his claim based on the results of corpus research and internet based acceptability rating experiments in which he found only a gradient difference between English and German. The experiments reported in the present paper show, however, that Featherston's conclusions are not warranted. In contrast to English, there is no general ban against crossing movement in German. When the two clause-mate wh-phrases differ in animacy, crossing movement in a transitive multiple question is as acceptable as noncrossing movement (Section 3, Experiments 3-5). ${ }^{2}$ This result is in line with what was found for other languages with free word order such as Czech, Polish, and Russian (Fedorenko and Gibson, submitted; Meyer 2004). However, when object and subject agree in animacy (Sections 2 and 3, Experiments 1, 2, and 6), object before subject order reduces acceptability. The effect seems absent in declarative sentences, but shows up again in questions with wh-phrase quantifier scope interactions (Experiment 7 in Section 4).

We argue that the animacy effect is a special case of the general need for having a motivation for the choice of a syntactically marked structure. For multiple questions, this motivation lies in the generation of different sorting keys for subject- and object-initial multiple questions. When both wh-pronouns are animate, word order differences are not accompanied by sorting key differences, so that the choice of a marked structure is not warranted.

Section 6 argues that syntacticians have judged and judge multiple questions in exactly the same way as the rest of the linguistic community. Section 7 is dedicated to a discussion of the difference between our findings in Experiments 1-7 and the result of the experiment reported in Featherston (2005).

\section{Crossing wh-dependencies involving pairs of animate wh-pronouns}

The COSMAS corpus of German texts (Institut für deutsche Sprache, Mannheim, of roughly one billion words) contains 1247 multiple questions 
involving a pronominal wh-subject (wer 'who') and a pronominal wh-object (982 instances of accusative wen, 265 of dative wem) in which both whpronouns are animate. ${ }^{3}$ All 1247 multiple questions begin with a wh-subject. Not a single instance of an object initial question can be found in the corpus (Featherston 2005).

There are also 1007 multiple questions formed with the subject wer and the inanimate object wh-pronoun was 'what'. Only 44 of these clauses $(=4.6 \%)$ are object initial (see Featherston 2005). The percentage of object initial structures in multiple questions is thus lower than the overall frequency of OVSstructures, which is $18.4 \%$ in the NEGRA Corpus (Weber and Müller 2004), and $20.4 \%$ in the Potsdamer Kommentar Korpus (Sauermann 2006). ${ }^{4}$

Featherston (2005) argues that the zero/low frequency of object-initial multiple questions with a subject-wh-pronoun constitutes evidence for an Englishlike superiority effect in German. The complete absence of crossing whmovement in sentences involving animate wh-pronouns in subject and object position in the COSMAS corpus is indeed striking and shows that examples such as (3) are "problematic".

(3) Wen hat wer verraten?
who.Acc has who.NOM betrayed
'Who betrayed who?'

Whether the status of (3) exemplifies a superiority effect in its standard sense cannot be answered independently of a consideration of questions such as (2), which combine an inanimate wh-object with a wer-subject. Recall that the latter type of multiple question can be found in corpora of German (though they are rare), which shows that the crossing constellation is not ungrammatical. Featherston (2005) presupposes a gradient concept of grammaticality, so that the low frequency of (2) could be an indication of reduced grammaticality in structures involving crossing movement.

Acceptability rating studies assess the perception of the well-formedness of constructions types more directly than corpus frequencies, and Featherston (2005) reports the result of an internet-based experiment with 38 subjects who saw 26 experimental items and 18 filler items and rated them with the Magnitude Estimation Method (see Cowart 1997; Keller 2000). He found that multiple questions with in situ wh-subjects (such as (4b)) are significantly less acceptable than other types of multiple questions such as (4a).
(4)
a. Wer hat dem Patienten was empfohlen?
who has the patient what recommended?
b. Was hat wer dem Patienten empfohlen? what has who the patient recommended 'Who recommended what to the patient?' 
There are several reasons for why one cannot be fully content with Featherston's experiment. First, he used a very complex design for the experiment, with 26 conditions, so that each participant saw only one experimental item per condition. ${ }^{5}$ The experimental items were constructed using 26 ditransitive sentence patterns such as (5), by replacing one or two of the arguments with a corresponding wh-phrase or by adding the question word wann. Given that there were only 38 participants, not more than 12 of the experimental items in each condition can have been rated by two or more participants.

(5) Der Zahnarzt hat dem Patienten die Zahnpasta
the dentist has the patient the toothpaste
empfohlen
recommended
'The dentist recommended the toothpaste to the patient'

The use of ditransitive rather than simple transitive constructions may have also led to unnecessary complications: speakers disagree as to whether they prefer the placement of the in situ wh-subject in front of the indirect object (as in (4b)), or behind it. We will return to this point below. Finally. the absence of a superiority effect in pairs corresponding to (2) in other free word order languages (for Czech see Meyer 2004; for Russian; see Fedorenko and Gibson submitted) leads to the expectation that the free word order language German should also lack superiority effects, so that the results concerning (4) may not be representative.

In order to find out whether the difference between animate and inanimate wh-objects found by Featherston (2005) in the COSMAS corpus is linked to a difference in acceptability, and whether the possible reduction of acceptability of crossing constructions is due to a superiority effect, we conducted a series of acceptability rating experiments.

\subsection{Experiment 1}

First, let us focus on multiple questions involving pairs of animate subjects and objects. When the two wh-phrases are pronominal, all such multiple questions are subject initial in the COSMAS corpus. Experiment 1 investigated whether the unattested object-initial version is less acceptable than its subject-initial counterpart. In addition, it compared crossing and noncrossing multiple questions that involve at least one nonpronominal wh-phrase.

In Experiment 1, the participants rated the acceptability of multiple questions of the type exemplified in (6). ${ }^{6}$ The multiple questions could either be subject or object initial (si/oi), and the wh-phrases could either be animate whpronouns $(p r)$ or animate which-phrases $(w p)$. The multiple questions thus 
appeared in 8 different versions, of which 4 were presented to each participant (4 items/condition). ${ }^{7}$ The first group of 19 participants saw those experimental items in which the two wh-phrases were either wh-pronouns or which-phrases (i.e., (6a)-(6d)). Twenty participants rated the experimental conditions in which the two wh-phrases had different values for the pronoun vs. which-factor (see (6e)-(6h)). In addition, the participants rated 72 distracter questions.

\begin{tabular}{|c|c|c|}
\hline$a$ & $\begin{array}{l}\text { Wer besticht wen an der Grenze? } \\
\text { who.NOM bribes who.ACC at the border }\end{array}$ & si; pr_pr \\
\hline b. & $\begin{array}{l}\text { Wen besticht wer an der Grenze? } \\
\text { 'Who bribes whom at the border?' }\end{array}$ & oi; pr_pr \\
\hline c. & $\begin{array}{l}\text { Welcher Ingenieur besticht welchen Forscher } \\
\text { which.NOM engineer bribes which scientist } \\
\text { an der Grenze? } \\
\text { at the border }\end{array}$ & si; wp_wp \\
\hline d. & $\begin{array}{l}\text { Welchen Forscher besticht welcher Ingenieur an der } \\
\text { Grenze? } \\
\text { 'Which engineer bribes which scientist at the border?' }\end{array}$ & oi; wp_wp \\
\hline e. & $\begin{array}{llll}\text { Wer besticht } & \text { welchen } & \text { Forscher an der } \\
\text { who.NOM bribes } & \text { which } & \text { scientist at the } \\
\text { Grenze? } & & & \\
\text { border }\end{array}$ & si; pr_wp \\
\hline $\mathrm{I}$ & $\begin{array}{l}\text { Welchen Forscher besticht wer an der Grenze? } \\
\text { 'Who bribes which scientist at the border?' }\end{array}$ & oi; wp_pr \\
\hline & $\begin{array}{llll}\text { Ingenieur } & \text { besticht } & \text { wen an der } \\
\text { engineer } & \text { bribes } & \text { who.ACC at the }\end{array}$ & si; wp_pr \\
\hline & $\begin{array}{l}\text { Wen besticht welcher Ingenieur an der Grenze? } \\
\text { 'Which engineer bribes who at the border' }\end{array}$ & oi; pr_wp \\
\hline
\end{tabular}

The results of Experiment 1 are given in Table 1. In the first subexperiment, on the seven-point scale used throughout this paper ( 1 being the worst, and 7 the best rating), subject initial multiple questions of the type (6a) got a mean rating of 5.39, while their object initial counterparts (6b) were judged as much worse

Table 1. Results of Experiment 1

\begin{tabular}{lll}
\hline & subject initial & object initial \\
\hline Pron: subject \& object & $5.39(6 \mathrm{a})$ & $2.44(6 \mathrm{~b})$ \\
Pron: None & $4.68(6 \mathrm{c})$ & $4.0(6 \mathrm{~d})$ \\
Pron: subject & $5.09(6 \mathrm{e})$ & $3.09(6 \mathrm{f})$ \\
Pron: object & $4.28(6 \mathrm{~g})$ & $4.11(6 \mathrm{~h})$ \\
\hline
\end{tabular}


$(2.44){ }^{8}$ The difference was highly significant $\left(\mathrm{F}_{1}(1,18)=62.44, \mathrm{p}<.001\right.$, $\left.\mathrm{F}_{2}(1,15)=92.14, \mathrm{p}<.001\right)$. Sentences with pairs of which-phrases also show an acceptability difference between subject-initial and object initial clauses (4.68 vs. 4.0). The difference was significant. $\mathrm{F}_{1}(1,18)=4.35, \mathrm{p}=.05$, $\left.\mathrm{F}_{2}(1,15)=9.31, \mathrm{p}<.001\right)$. There was a marginal main effect of the type of the wh-phrase $\left(\mathrm{F}_{1}(1,18)=6.86, \mathrm{p}<.05, \mathrm{~F}_{2}(1,15)=2.23, \mathrm{p}=.16\right)$, and a main effect of word order $\left(\mathrm{F}_{1}(1,18)=42.39, \mathrm{p}<.0001, \mathrm{~F}_{2}(1,15)=75.64, \mathrm{p}<.0001\right)$. The interaction between the two factors was significant $\left(\mathrm{F}_{1}(1,18)=27.18, \mathrm{p}<\right.$ $\left..0001, \mathrm{~F}_{2}(1,15)=36.63, \mathrm{p}<.0001\right)$ : the loss of acceptability in crossing multiple questions is higher for pronominal wh-subjects than for which-subjects.

The second half of the experiment working with structures such as (6e)-(6h) had a comparable result. ${ }^{9}$ There was a main effect of the type of the clause initial wh-phrase $\left(\mathrm{F}_{1}(1,18)=18.12, \mathrm{p}<.001, \mathrm{~F}_{2}(1,15)=13.49, \mathrm{p}<.01\right)$ and of word order $\left(\mathrm{F}_{1}(1,18)=25.26, \mathrm{p}<.0001, \mathrm{~F}_{2}(1,15)=20.23, \mathrm{p}<.001\right)$, but the two factors did not interact $\left(\mathrm{F}_{1}<1, \mathrm{~F}_{2}<1\right)$.

Experiment 1 establishes two points. First, multiple questions with two animate wh-phrases are in general more acceptable when they are subject-initial than when they begin with a wh-object. This even holds for pairs of whichphrases such as (6c) vs. (6d). This finding is not necessarily surprising, because object initial sentences are in general less acceptable in German than their subject-initial counterparts, at least when they are not presented in a context licensing object initiality (Fanselow et al. [2008]; see also Haupt et al. [2008] for more details concerning the disadvantage of object initial sentences). Similarly, object initial questions are less acceptable than subject initial questions in English even when no crossing is involved (Arnon et al. 2005).

This overall reduction in the acceptability of object initial questions does not suffice to explain the results concerning (6a)-(6d). An interaction between the type of the wh-phrase (pronoun vs. 'which') and word order (subject vs. object initiality) came out very clearly in the first subexperiment: the loss in acceptability in object initial multiple questions is significantly larger for pairs of wh-pronouns than for which-phrases. The pattern of acceptability found in (6a)-(6d) is therefore reminiscent of the English superiority effect. Acceptability judgments for multiple questions with a fronted animate object wh-pronoun and the in situ subject wh-pronoun are in line with the corpus results: such questions do not occur, and their acceptability is significantly lower than the one of their subject-initial counterparts.

\subsection{Experiment 2}

We replicated the result for pronominal wh-subjects in Experiment 2, which appeared among the distracter items of a large study investigating the grammar 
of German discontinuous noun phrases with several independent questionnaires. Experiment 2 focused on the contrast exemplified in (7): the participants had to rate multiple questions with two animate wh-pronouns. The in situ wh-phrase always followed the discourse particle denn, which, at least according to Diesing (1992), marks the boundary of the verbal projection in which the subject is base generated (vP). The multiple questions could either be subject (si) or object initial (oi). Each participant saw 4 items in each of the two conditions. The eight experimental items appeared among the distracters on 37 different questionnaires (with 76-80 further items) which were rated by 8 participants each, i.e., there were 296 participants in the experiment.

(7) a. Wer hat denn wen eingeladen? si who.NOM has ptc. who.ACC invited

b. Wen hat denn wer eingeladen?

oi

'Who invited who?'

Subject initial questions got a mean rating of 6.13 , while the mean rating of their object initial counterparts was at $3.39\left(\mathrm{~F}_{1}(1,295)=708.96, \mathrm{p}<.001\right.$, $\left.\mathrm{F}_{2}(1,7)=4006.6, \mathrm{p}<.001\right)$. Experiment 2 thus confirms that crossing movement causes a considerable loss of acceptability in multiple questions with pairs of wh-pronouns. ${ }^{10}$

\section{Effects of inanimate wh-objects crossing animate wh-subjects}

The first two experiments seem to support the view that the superiority condition has an impact on German multiple questions, but our database is still too small for drawing firm conclusions. Meyer (2004) made an important observation concerning animacy and superiority. In his experiments focusing on Slavic multiple questions, he found a stable reduction of acceptability when an animate wh-object is placed in front of an animate wh-subject. In some Slavic languages (Czech, Polish), no crossing effect could be detected when an inanimate wh-object was moved across an animate wh-subject pronoun. ${ }^{11}$

\subsection{Experiment 3}

In order to find out whether German patterns with Czech and Polish in this respect, we constructed a rating experiment (Experiment 3) that compared the acceptability of sentences such as (8). Experiment 3 was embedded in a larger written questionnaire study (viz., Experiment 1 of Fanselow and Frisch 2006), and was presented to 20 of the 43 subjects. In addition to the 8 experimental items (4 per condition), there were 8 related filler items and 
90 unrelated filler items. ${ }^{12}$ The 106 sentences were presented in a pseudorandomized order.
a. Wer hat was für das heutige Treffen who has what for the today meeting lesen sollen? read should 'Who was supposed to read what for today's meeting?'
b. Was hat wer für das heutige Treffen lesen sollen? (object initial)
(subject initial)

Mean acceptability was 4.42 for the subject-initial condition, and 4.38 for the object-initial one, i.e., the participants of the experiment found was-initial multiple questions $(8 \mathrm{~b})$ as acceptable as wer-initial ones $(8 \mathrm{a})\left(\mathrm{F}_{1,2}<1\right) .{ }^{13}$ In other words, there was no superiority effect visible at all for multiple questions with an inanimate object. This result harmonizes with what was found in other free word order languages (Czech, Polish, Russian).

\subsection{Experiment 4}

Experiment 4 differs from the other experiments of this paper in a number of dimensions. First, the material was presented auditorily rather than in written form. ${ }^{14}$ The obvious advantage of this presentation mode is that a potentially disturbing factor can be controlled: like most German wh-pronouns, the forms wer, was, and wen are ambiguous between a question and an indefinite pronoun interpretation. Example (9) allows the two readings indicated in the translation. If wer is interpreted as a second question phrase, (9) involves a crossing constellation. With an indefinite interpretation of wer, (9) is just a single question, so that issues of crossing and superiority do not arise at all. Disambiguation follows a simple pattern: wh-pronouns in Spec,CP and accented wh-pronouns are interpreted as question words, the other occurrences of wh-pronouns are indefinites. ${ }^{15}$
(9) Wann hat wer angerufen?
when has who called
'Who called when?'
'did someone call?'

This ambiguity makes the interpretation of the results of written questionnaire studies somewhat difficult, although the indefinite interpretation of the whword can be shown to be dispreferred. When subjects are asked to read out sentence material involving two wh-pronouns, they nearly always stress both wh-pronouns, i.e., the phonological realization shows that they analyze the in situ wh-pronoun as a question operator (Fanselow and Féry 2008). 
In Experiment 4, the in situ wh-phrase was always pronounced with an accent, so that it did not allow an indefinite interpretation. The 24 participants heard 8 items for each of the four conditions exemplified in (10). All experimental items were multiple questions formed with two wh-pronouns that figured as subjects and objects, respectively. The items could be subject or object initial. The subject was wer 'who.NOM', while the object could be animate wen 'who.ACC' or inanimate was 'what.ACC'
a. Wer hat wen im Garten besucht? who.NOM has who.ACC in-the garden visited
b. Wen hat wer im Garten besucht?
c. Wer hat was im Keller gesucht? who has what in-the basement searched 'Who looked for what in the basement'
d. Was hat wer im Keller gesucht?

In addition, participants heard 16 related filler items (multiple questions constructed with an inanimate subject, see Note 18 below), 24 multiple questions with agreement violations, and 152 unrelated filler items. By pressing a button after being visually prompted for doing so, participants indicated whether they found the sentence acceptable or not. Reaction time ( $=$ the time between the visual solicitation of the reaction and the pressing of the button) was recorded as well. Trials with a reaction time longer than 3 seconds have been discarded from the analysis ( 27 out of the 960 trials involving the 4 experimental conditions and the 16 related fillers, $2.8 \%)^{16}$

The results of Experiment 4 are given in Table 2. The statistical analysis for the mean rejections revealed a main effect of word order $\left(\mathrm{F}_{1}(1,19)=15.659\right.$, $\mathrm{p}<.001 ; \mathrm{F}_{2}(1,31)=71.818, \mathrm{p}<.001$; due to more rejections in the object initial conditions $(16.25 \%)$ than in the subject initial conditions (1.98\%). It also indicated as a main effect the animacy of the object $\left(\mathrm{F}_{1}(1,19)=17.299\right.$, $\mathrm{p}<.001 ; \mathrm{F}_{2}(1,31)=85.049, \mathrm{p}<.001 ;$ due to more rejections in the object initial conditions in general, and particularly in the animate object $>$ subject condition (30.0\%). More interestingly, there was an interaction between both factors $\left(\mathrm{F}_{1}(1,19)=20.974, \mathrm{p}<.001 ; \mathrm{F}_{2}(1,31)=37.151, \mathrm{p}<.001\right)$. Resolving this interaction revealed that the sentences of the object initial conditions were significantly more often rejected than sentences of the SO conditions for the

Table 2. Results of Experiment 4

\begin{tabular}{lll}
\hline & subject initial & object initial \\
\hline animate object & $97.5 \%(10 \mathrm{a})$ & $70.0 \%(10 \mathrm{~b})$ \\
inanimate object & $98.5 \%(10 \mathrm{c})$ & $97.5 \%(10 \mathrm{~d})$ \\
\hline
\end{tabular}


pattern with two animate wh-pronouns, $\left(\mathrm{F}_{1}(1,19)=19.319, \mathrm{p}<.001 ; \mathrm{F}_{2}(1,31)\right.$ $=77.412, \mathrm{p}<.001)$. However there was no significant contrast in the conditions with inanimate objects $\left(\mathrm{F}_{1}<1 ; \mathrm{F}_{2}<1\right)$.

Subject initial sentences were accepted by the participants to a very high degree, and it plays no role whether the wh-object left in situ is animate. This is what one would expect. Results are different when the wh-object is fronted and the animate subject wh-pronoun stays in situ. In line with Experiment 1 and 2, acceptance went down from 97.5 to 70.0 percent for fronted animate wh-objects. For fronted inanimate wh-objects, acceptability was not decreased in a statistically relevant way $(98.5 \%$ vs. $97.5 \%) .{ }^{17}$

Experiment 4 thus confirms the findings of the previous three experiments. There is a difference in acceptability between crossing and noncrossing whquestions if the crossing wh-pronoun is animate, but this effect cannot be due to a general superiority condition, since the use of an inanimate object whpronoun eliminates this difference: both orders are accepted more than $97 \%$ of the time, they are both well-formed structures of German. The crossing effects in multiple questions in German and English are qualitatively different.

\section{Wh-objects crossing inanimate wh-subjects}

Crossing wh-movement comes with no decrease in acceptability when an inanimate object is moved to the left of an animate subject, while acceptability goes down when the animate subject is crossed by an animate object. The idea suggests itself that one will find the same dissimilarity effect when the subject is inanimate. We investigated this issue in two further experiments.

\subsection{Experiment 5}

Inanimate wh-subjects were combined with animate wh-objects in Experiment 5. In the experimental items, the object always was the wh-pronoun wen 'who. ACC'. The subject could be was 'what' in the pron(ominal) condition, and was composed of welcher 'which' and an inanimate noun in the wp condition. Sentences could be subject or object initial. In the construction of the material, we avoided psychological predicates because these often come with an object $>$ subject normal order (see Haider and Rosengren 2003) that would make it hard to decide if a given multiple question involves a crossing constellation or not. The experimental conditions are exemplified in (11).
a. Welcher Anruf erreichte wen? si; wp
b. Wen erreichte welcher Anruf?
'Which call reached who?' 
Table 3. Results of Experiment 5

\begin{tabular}{lll}
\hline & subject initial & object initial \\
\hline pronominal subject & $5.65(11 \mathrm{c})$ & $5.7(11 \mathrm{~d})$ \\
which-subject & $5.62(11 \mathrm{a})$ & $5.65(11 \mathrm{~b})$ \\
\hline
\end{tabular}
c. Was erreichte wen?
si; pron what reached who
d. Wen erreichte was?
oi; pron

48 students rated 4 items per condition (and further 96 distracter items) on our seven-point scale. The mean acceptability for sentences such as (11a) was 5.62 , for sentences such as (11b) it was 5.65. When the subject was the inanimate wh-pronoun was, subject $>$ object order (11c) yielded a mean acceptability of 5.65, and the mean acceptability of the inverse order was 5.70. Neither the factor subject/object initiality nor the factor \pm pronoun yielded a significant contrast $\left(\mathrm{F}_{1,2}<1\right)$ and there was no significant interaction between the two factors either $\left(\mathrm{F}_{1,2}<1\right)$.

Although the absence of a significant difference cannot be interpreted easily, Experiment 5 suggests that crossing movement does not imply a reduction of acceptability when the two wh-phrases do not agree in animacy. This result is independent of whether the animate wh-pronoun is the subject or the object in the sentence.

\subsection{Experiment 6}

This leaves us with the issue of whether there is a crossing effect in the case of two inanimate wh-phrases, too. In the pertinent Experiment 6, we could not use pairs of inanimate wh-pronouns, since was does not distinguish nominative and accusative case, and has no dative form. (12) is thus globally ambiguous, and cannot be used in experiments that try to distinguish the acceptability of subject- and object-initial forms. Instead of (12), we used multiple questions in which one argument slot was filled by was, while the other argument was a which-phrase with an inanimate nominal head. In the experimental items, the pronoun could either be the subject or the object (pron_sub vs. pron_obj), and the question could be subject or object initial (si vs. oi). These conditions are exemplified in (13).

(12) Was erforderte was?

What required what

'What required what?' 
Table 4. Results of Experiment 6

\begin{tabular}{lll}
\hline & subject initial & object initial \\
\hline pronominal subject & $5.48(13 \mathrm{a})$ & $3.96(13 \mathrm{~b})$ \\
which subject & $6.1(13 \mathrm{c})$ & $5.88(13 \mathrm{~d})$ \\
\hline
\end{tabular}

a. Was erforderte welchen Abschluss? Pron_sub si what required which.ACc degree

b. Welchen Abschluss erforderte was? Pron_sub oi 'What required which degress?'

c. Welcher Abschluss erforderte was? Pron_obj si which.NOM degree required what

d. Was erforderte welcher Abschluss? Pron_obj oi 'Which degree required what?'

Together with 34 distracter items, 4 items per conditions were presented to 24 students. The results of the experiment are represented in Table 4. In multiple questions with an inanimate which-phrase in subject position, the subjectinitial version has a slightly higher (6.1 vs. 5.88) mean acceptability score than the version in which the subject is crossed over by was. For sentences in which was is the subject, we found a large difference in the acceptability of subject vs. object initial questions (5.48 vs. 3.96).

Both the contrasts of the factor \pm pronominal subject $\left(\mathrm{F}_{1}(1,23)=33.07\right.$, $\left.\mathrm{p}<.001 ; \mathrm{F}_{2}(1,15)=43.91, \mathrm{p}<.001\right)$ and of the factor subject/object initiality $\left.\left(\mathrm{F}_{1}(1,23)=20.34, \mathrm{p}<.001 ; \mathrm{F}_{2}(1,15)=17.05, \mathrm{p}<0.001\right)\right)$ were statistically significant, as was the interaction between them $\left(\mathrm{F}_{1}(1,23)=13.28, \mathrm{p}<0.01\right.$; $\left.\mathrm{F}_{2}(1,15)=9.15, \mathrm{p}<0.01\right)$. A one-factor ANOVA showed that the contrast between $(13 a)$ and $(13 b)$ was significant, $\left(F_{1}(1,23)=21.64, p<0.001 ; F_{2}(1,15)=\right.$ $17.23, p<0.001)$ but not the one between $(13 \mathrm{c})$ and $(13 \mathrm{~d})\left(\mathrm{F}_{1}(1,23)=1.6\right.$, $\left.\mathrm{p}=0.21 ; \mathrm{F}_{2}(1,15)=1.1, \mathrm{p}<0.31\right)$.

Experiment 6 thus supports the hypothesis that acceptability is decreased by crossing movement in those multiple questions only in which the crossing whobject and the wh-subject agree in animacy. ${ }^{18}$ The effect shows up very clearly for the wh-pronouns wer and was. ${ }^{19}$

\section{Towards an understanding of the animacy effect}

\subsection{Processing}

There is no general ban against crossing wh-movement in German, but acceptability is reduced when the crossing occurs in a constellation in which the two 
wh-phrases agree in animacy. The former observation supports grammatical models such as Chomsky (2005) without a constraint implying intervention effects. The latter observation is not predicted by independently motivated syntactic principles, and calls for an explanation.

The animacy effect is reminiscent of what Haider $(1997,2000)$ discovered concerning Case in multiple questions: while wh-objects can cross each other (14a), acceptability goes down in crossing structures when the two wh-phrases bear the same Case (14b) (see also Fanselow and Féry 2008). Haider argues convincingly that the lower acceptability of (14b) is due to a processing problem, and we envisage a similar account for the animacy effect.
a. Wen hat er wem geholfen $\mathrm{t}_{\mathrm{wen}}$ davon zu informieren? who.ACC has he who.DAT helped thereof to inform
'Who has he helped to inform who about that'
b. Wem hat er wem geholfen $\mathrm{t}_{\mathrm{wem}}$ dies zu erklären? who.DAT has he who.DAT helped this to explain 'Who has he helped to explain this to whom?'

In principle, in a processing account the animacy effect could be related to the concept of "unmarked transitivity" and the processing costs of violations thereof. The unmarked transitive pattern involves an animate subject and an inanimate object (Comrie 1989), and its unmarkedness goes hand in hand with the processing principle Distinctness proposed by Schlesewsky and Bornkessel (2004). Distinctness requires that each argument be maximally distinct from every other argument in terms of thematic status. The principle explains, e.g., the additional processing costs that can be observed in marked word order sentences when the arguments of a predicate agree in animacy (Schlesewsky and Bornkessel 2004; Schlesewsky and Bornkessel-Schlesewsky 2009). An increase in processing difficulty often reduces the acceptability of sentences (Fanselow and Frisch 2006), so that Distinctness can be invoked in an account of the animacy effect.

One must acknowledge, however, that object movement to Spec,CP in sentences with two arguments not differing in animacy is not always inacceptable. Fanselow et al. (2008) compared the (focus-induced) fronting of animate and inanimate objects across an animate subject as in (15), and found no acceptability difference between such structures

(15) a. Den serbischen Studenten mag der Professor
the.ACC Serbian student likes the professor
besonders.
particularly
'The professor particularly likes the student from Serbia.'


b. Den serbischen Bohneneintopf mag der Professor the.ACC Serbian bean pot likes the professor besonders particularly 'The professor particularly likes the Serbian bean pot.'

We obtained the same negative outcome in a further experiment involving pairs of indefinite rather than definite noun phrases. We asked 24 participants to rate the acceptability of 4 sentences each for the two conditions exemplified in (16), in which an animate subject was crossed by inanimate (16a) and animate objects (16b). The acceptability of such sentences turned out to be fairly low (3.43 for sentences with inanimate objects, and 3.52 for sentences with animate objects), but the conditions did not differ significantly.
a. Keinen Bohneneintopf mag fast jeder dritte no.ACC beans pot likes nearly every.NOM third Pfarrer priest.
'Nearly every third priest does not like beans pot' no.ACC atheist likes nearly every.NOM third priest 'Nearly every third priest likes no atheists'
b. Keinen Atheisten mag fast jeder dritte Pfarrer.

\subsection{Experiment 7}

Wh-phrase quantifier interactions are the only constellation for which we have been able to come close to detecting a further instance of the animacy effect. The 24 participants of the study just reported also saw 8 sentences ( 4 per condition) of the type exemplified in (17), in addition to further 72 distracter items.
a. Vor der Party wollte die Gastgeberin wissen wen before the party wanted the host-FEM know who.ACC jeder mitbringen wollte everyone.NOM bring wanted 'Before the party, the host wanted to know who everyone wanted to bring'

b. Vor der Party wollte die Gastgeberin wissen, was before the party wanted the host.Fem know what jeder mitbringen wollte everyone.nom bring wanted 'Before the party, the host wanted to know what everyone wanted to bring'

In all experimental sentences, a wh-object crossed a quantified subject, viz. the bare quantifier jeder 'everyone' in an embedded clause. The wh-phrase was a 
wh-pronoun, and could be animate (17a) or inanimate (17b). Examples were constructed such that a wide scope interpretation of the quantifier was likely. Under this interpretation, the experimental items bear the meaning of a (pair list interpreted) multiple question: if one asks, for every $x$, which $y$ stands in the relation $R$ to $x$, then one asks for the pairs $\langle x, y\rangle$ that stand in the relation $R$ to each other.

The mean rating of the animate wh-condition was $5.26(=17 \mathrm{a})$ the mean rating for the inanimate wh-condition was $5.75(=17 \mathrm{~b})$. The difference was significant in the subject analysis $\left(\mathrm{F}_{1}(1,23)=7.99, \mathrm{p}=.01\right)$, but not in the item analysis $\left(\left(\mathrm{F}_{2}(1,7)=1.98, \mathrm{p}>.20\right)\right)$.

The failure of reaching the level of significance in the item analysis suggests that our experimental material was not constructed in a fully optimal fashion. The interpretation of Experiment 7 is also made difficult by the fact that we do not know whether judgments were actually given relative to a wide scope interpretation for the quantified subject (as intended) or not. Even with these provisos, it is still interesting to observe that a (weak) animacy effect arises in a structure with the meaning (but not the syntax) of a multiple question. ${ }^{20}$

\subsection{Sorting keys}

The animacy effect is absent in structures such as (15) and (16) that differ from multiple questions and sentences like (17) in an important way. In the declarative sentences, the movement of the object is motivated on a number of grounds, such as focality, topic shift, contrast, etc. The subject crossed over need not (and sometimes, cannot) have the same function, i.e., the animacy effect is absent when the subject and object are distinct in terms of their discourse function. In other words, there is a penalty for congruent animacy in crossing movement constellations only if the crossing movement adds no extra semantic or discourse value.

More precisely, we interpret the animacy effect in terms of the sorting key idea proposed (cf., e.g., Comorovski (1996), and others: the wh-phrase in Spec,CP serves as the "topic" of the question. Therefore, the information requests are shaped in different ways in (18). (18a) asks to provide, for each member $x$ of a contextually given set of girls, the CDs that $x$ bought. Example (18b) asks to provide, for each member $x$ of a contextually given set of CDs, the girls that bought $x$. The movement of the object (rather than the subject) in (18b) is thus licensed because it leads to a different sorting key.

(18) a. Which girl bought which CD?

b. Which CD did which girl buy? 
In contrast, wh-pronouns have very little semantic content, which reduces their ability to induce differences in sorting keys. However, in case two wh-pronouns differ in animacy, a sorting key difference based on crossing vs. noncrossing movement can be constructed. Example (19a) asks to indicate: for all $x$ in a contextually given set of animates/humans, what object $y$ was seen by $x$. (19b) asks to provide, for all $x$ from a contextually given set of inanimates, the human $y$ that saw $x$. The sorting keys of the questions in (19c) and (19d) are identical, however; it is always the set of contextually given humans (animates), because the two wh-pronouns do not differ semantically,
a. Wer hat was gesehen?
who has what seen
'Who saw what?'
b. Was hat wer gesehen?
c. Wer hat wen gesehen?
who.NOM has who.ACC seen
'Who saw who?'
d. Wen hat wer gesehen?

Suppose, then, that object initial structures are more marked than subject initial ones (because they involve more movement steps, or longer ones) although they are grammatical, and can be chosen only if this choice is motivated because of some interpretive effect. (19b) then comes without a problem (because of the sorting key difference described above), while (19a) is inacceptable: the choice of the more marked object initial structure has no effect on sorting keys in (19d), and is thus not warranted. ${ }^{21}$

\section{Judgments of linguists vs. judgments of linguistically naïve participants}

The major finding of the present paper lies in the identification of an animacy effect on crossing movement in German. Apart from that effect, crossing movement turns out to be as acceptable as its noncrossing counterpart (though the general difficulties of object initial sentences may sometimes influence acceptability). The syntactic literature on German (with the exception of Featherston 2005, of course) nearly unanimously presupposes that there is no general ban on crossing movement in German, and is thus in harmony with the findings reported here. Our experiments have confirmed the general position concerning superiority effects taken by syntacticians.

The loss of acceptability that results when a (pronominal) wh-subject is crossed by a (pronominal) wh-object with which it agrees in animacy was not noted explicitly in the syntactic literature. This does not imply that there was a 
misrepresentation of acceptability facts in the syntax articles. Rather, nearly all illustrations of the absence of a superiority effect in German one can find in the literature involve was-wer pairs. The acceptability of corresponding sentences with two animate wh-phrases is practically never discussed at all in these publications.

(20) a. Weißt du noch was wer bestellt hat? know you still what who ordered has?

'Do you still know who has ordered what?' (Haider 1986: 292)

b. Was hat wer gekauft? what has who bought

'Who bought what?' (Noonan 1988: 17)

c. Was hat wer behauptet?

what has who claimed

'Who claimed what?'

(Grewendorf 1988: 312; Müller 1995: 276)

The animacy effect has thus been indirectly "acknowledged" in the linguistic literature, by confining illustrations of the absence of a superiority condition effect to sentences with wh-phrases differing in animacy. There are rare instances of hints at the animacy contrast, as in Fanselow (1991: 329), who discusses prosodic and pragmatic constraints on the acceptability of (22a) and observes that (22b) is not subject to such restrictions, but he fails to link explicitly the contrast to animacy.
a. Ich habe vergessen,
wen wer umbringen wollte
I have forgotten who.ACC who.NOM kill
wanted
'I have forgotten who wanted to kill who'
b. Er wollte wissen, was jeweils wer vorgetragen hatte he wanted know what resp. who presented had 'He wanted to know who had presented what'

Acceptability facts for German multiple questions were thus rarely misrepresented in the theoretical literature (if at all).

It may be interesting to find out systematically how syntacticians rate the two examples in (21), but judgments one could collect now might be influenced by the theoretical predictions concerning the contrast in nearly all current accounts for German. However, crossing movement with inanimate subjects as in Experiment 6 has never been considered in the literature, so that professional judgments are less likely based on previous assessments of these sentences in the literature. As a pilot for Experiment 6, we interviewed syntacticians with 
Table 5. Judgments of syntacticians

\begin{tabular}{lll}
\hline & subject initial & object initial \\
\hline animate object & $6.7(13 \mathrm{a})$ & $5.6(13 \mathrm{~b})$ \\
inanimate object & $6.4(13 \mathrm{c})$ & $4.0(13 \mathrm{~d})$ \\
\hline
\end{tabular}

respect to such structures, by sending out 20 multiple questions electronically to a number of linguists, of which 18 responded by rating them on our sevenpoint scale. The four conditions exemplified in (22) appeared with 4 items each. The subject was the inanimate wh-pronoun was, the object could be an inanimate as in (22a) and (22b) or an animate which-phrase as in (22c) and (22d). Different verbs were used for the different object types, to increase plausibility. The other factor was, as always, subject- or object initiality. The remaining four sentences were multiple questions formed with warum 'why'. The results of this study are given in Table 5 .
a. Was erklärte welchen Befund?
what explained which.acc result
'What explained which result?'
b. Welchen Befund erklärte was?
c. Was störte welchen Professor?
what annoyed which.ACC professor
'What annoyed which professor?'
d. Welchen Professor störte was

The subject initial conditions got a very high rating (6.7 and 6.4 for animate and inanimate objects, respectively). With animate objects, acceptability decreased in the crossing condition (5.6); but the magnitude of the decrease is relatively small. In contrast, the acceptability of inanimate objects fronted across inanimate subjects was low (4.0), the size of the difference is reminiscent of what we saw the comparable cases of two animate wh-phrases. ${ }^{22}$ By and large, we can conclude that syntacticians showed the behavior that we observed in Experiment 6: They even saw a small contrast in the case of wh-pairs not agreeing in animacy. ${ }^{23}$

There is little reason to believe, then, that syntacticians or linguists in general judge multiple questions in a way much different from the rest of the linguistic community. Also the literature does not contain false statements concerning the acceptability of crossing movement. The only potential problem of the previous presentation of facts lies in the failure to discuss explicitly the animacy effect: it was "filtered out" for the purposes of model formation. The (implicit) background assumption may have been that this effect is due to some noise factor such as the constructability of different sorting keys. 


\section{Transitive and intransitive clauses: Experiment 8}

As remarked above, it is generally believed that the problem of conflicting judgments and gradient contrasts in acceptability can be solved by the use of controlled acceptability rating experiments. The results in this paper show that this is not necessarily so: there is a conflict between the results we obtained for crossing movement, and the superiority experiment described in Featherston (2005) in the case of wh-pronouns differing in animacy.

The different results may have various sources. In principle, the choice of method may matter: while we used a seven-point scale, Featherston's participants rated the sentences with the technique of Magnitude Estimation, which is sometimes claimed to be more sensitive that judgments on a scale. The results of Bader and Häusler (2010) and Weskott and Fanselow (2008, 2009, forthcoming) cast doubt on the validity of this attempt of understanding the different results. If there is a difference at all in sensitivity between the two methods, scales may be the ones that show more fine-grained details. Still, we found it sensible to have the type of sentences used by Featherston judged in a scale-based experiment.

One obvious difference between Featherston's material and ours lies in the fact that the former was constructed with ditransitive verbs, and the latter with transitives. The additional presence of a non-wh indirect object should not have any direct effect on the grammaticality of a wh-object moving across a wh-subject. However, the linearization of the subject relative to the indirect object may be difficult when the direct object moves to Spec,CP. Consider (23) in this respect:
a. Wer
hat dem
Peter was
empfohlen?
who.NOM has the.DAT Peter what recommended?
'Who recommended Peter what?'
b. Wer hat was dem Peter empfohlen?
c. Was hat wer dem Peter empfohlen?
d. Was hat dem Peter wer empfohlen?

(Animate) indirect objects precede (inanimate) direct objects in normal order, so that the arguments of empfehlen 'recommend' are serialized canonically in (23a). (23a) is also unmarked from a further perspective. Recall that in situ wh-words must be accented in German. The direct object was appears in prefinal position in (23a), preceding the verbal participle, in the unmarked position for accents in German, which is perceptually salient because the verb is usually deaccented. In contrast, $(23 \mathrm{~b})$ should be worse, because was is scrambled away from the default preverbal focus position, which either increases the distance between the final accent and the right sentence boundary (in which case dem Peter is deaccented) or presupposes a contrastive interpretation for dem Peter. 
When the direct object is fronted as in (23c)-(23d), the wh-subject needs to be accented. In (23c), it either precedes a deaccented indirect object integrated with the deaccented verbal participle, which results in a large distance between the accented phrase and the right sentence boundary that should reduce acceptability. If dem Peter is accented, it must be read contrastively, but this interpretation would not be warranted in an out-of-the-blue presentation of the sentence. By scrambling the indirect object in front of the subject, one can solve the phonological phrasing problem, but this comes at a cost because scrambling always reduces acceptability. Therefore, there may be no good solution for serializing the subject and the indirect object in an object-initial multiple question in German. This would render the crossing movement constellation less acceptable than the subject initial clause.

In Experiment 8, we did not attempt to closely replicate the experiment reported in Featherston (2005). Instead, we stuck to the method of rating on a 7-point scale, and to the standard design of presenting 4 items per condition to each participant, and presenting each item to an equal number of participants. In addition, we did not only compare (23a) with (23c), but also added sentences in which the in situ subject appeared in the immediately preverbal position, for the reasons discussed above. In order to balance the design, we introduced a word order alternation in the subject initial questions, too $(=23 \mathrm{~b})$.

24 students rated four sentences in each of the following four conditions:

subject initial, dative $>$ wh in situ (=23a)

subject initial, wh in situ $>$ dative (_23b)

object initial, dative $>$ wh in situ $(=23 \mathrm{~d})$

object initial, wh in situ $>$ dative (_23c)

The results of Experiment 8 are given in Table 7. Subject initial sentences were significantly more acceptable than their object initial counterparts $\left(\mathrm{F}_{1}(1,23)=\right.$ $32.58, \mathrm{p}<.001, \mathrm{~F}_{2}(1,15)=300.43, \mathrm{p}<.001$, but the factor concerning the order of the dative and the in situ wh-phrase showed no effect $\left(\mathrm{F}_{1,2}<1\right)$. However, there was a significant interaction between the two factors $\left(\mathrm{F}_{1}(1,23)=\right.$ $10.15, p=.004, F_{2}(1,15)=14,67, p<.001$. The effect of a change of the position of the in situ wh-element was larger in the subject initial condition than in the object initial condition.

Table 6. Results of Experiment 8

\begin{tabular}{lll}
\hline & subject initial & object initial \\
\hline dat $>$ wh & $5.9(23 \mathrm{a})$ & $3.4(23 \mathrm{~d})$ \\
$\mathrm{wh}>$ dat & $5.3(23 \mathrm{~b})$ & $3.7(23 \mathrm{c})$ \\
\hline
\end{tabular}


That multiple questions formed with ditransitive verbs show a stable contrast in acceptability between crossing and noncrossing movement even when the two wh-pronouns differ in animacy certainly comes as a surprise, even in the light of our discussion of possible independent problems with object initial sentences of the type (23c) and (23d). The absence of such a decline in acceptability for crossing movement in our experiments with transitive verbs, and in the studies concerned with other free word order languages, constitutes firm evidence for the hypothesis that crossing movement is not ruled out when sorting key differences can be constructed. There is no reason to believe that sorting key construction is different with ditransitive verbs, so that the effect in Experiment 8 must be due to peripheral properties of the items. Above, we made some suggestions concerning these peripheral properties, but the size of the effect is somewhat mysterious. The clarification of this issue will have to be left to future research.

\section{Conclusions}

The English superiority effect exemplified in (1) is a poorly understood phenomenon. It does not really follow from any of the current grammatical models, and it can become invisible under certain pragmatic (Bolinger 1978) and semantic (Reinhart 1995) circumstances. Furthermore, the literature concurs in the assumption that a comparable effect does not hold in free word order languages such as German, Japanese, Spanish, and the Slavic languages, and in some fixed order languages such as Swedish.

Our experiments shed little light on the English situation, but they corroborate the view that free word order languages lack a superiority effect. However, the choice of a marked word order must be justified in free constituent order languages, too, so multiple questions with crossing movement are considered as acceptable as noncrossing questions only when they come with a sorting key difference. Wh-pronouns have little semantic content, and when they have identical semantic features, they cannot support sorting key differences, so that crossing movement is ruled out in such constellations even in German or Slavic.

Received 18 October 2007

Revised version received 3 September 2009
University of Potsdam

University of Mainz

University of Bielefeld

\section{Appendix. The experiments}

Unless indicated otherwise, all experiments reported in this paper were carried out in exactly the same way. 


\section{Participants}

The participants of the experiments were students of the University of Potsdam, with the exception of Experiment 2, in which students of the Humboldt University and Brandenburg high school students (recruited on the campus of the University of Potsdam during its annual public relations event) also participated. They were paid for participation, or participated in the experiment in order to fulfill curricular requirements.

\section{Method}

The participants rated the acceptability of the experimental items embedded in a set of distracter items (appearing in pseudo-randomized order) on a printed questionnaire or on a computer screen (Experiment 2). Most experiments used a seven-point rating scale ( 1 worst, 7 best). A six-point rating scale ( 1 best, 6 worst) had been used in Experiments 1 and 4 . The scale appeared below each item on the printed questionnaire or the screen, and subjects responded by ticking the appropriate number or by pressing the corresponding key. The scale was explained and exemplified in the instruction part of the experiment. The two items exemplifying the scale consisted of one fully grammatical and one fully ungrammatical sentence.

\section{Material}

With the exception of Experiment 4, participants always saw 4 items per condition. For each experiment with $n$ conditions, we constructed $4 n$ blocks of $n$ sentences not sharing any lexical material, such that each experimental condition was realized in each of these blocks. The questionnaires were constructed in $n$ versions, such that each participant saw exactly one sentence from each block only. The sentences of each block were rated by exactly the same number of conditions

\section{Notes}

1. The research reported here was supported by DFG-grants FOR 375-A3 and FAN 255/6 to the University of Potsdam. We are very grateful to Joanna Błaszczak, Heiner Drenhaus, Susann Fischer, Stefan Frisch, and Arthur Stepanov, who were linked to project A3 of FOR 375, and contributed to the work reported here. Furthermore, we are much indebted to Caroline Féry, Lyn Frazier, Hubert Haider, Frank Kügler, Pawel Logačev, Gereon Müller, and Stefan Müller, and to the two anonymous reviewers. A final thank goes to Jutta Boethke, Klaus Didakowski, Pavel Logačev, Ewa Trutkowski, Julia Vogel, Nic Werner, Nora Winter, Kathrin Wrede, and Marco Zugck for technical support. Correspondence address: Gisbert Fanselow, Institut für Linguistik, Universität Potsdam, Postfach 601553, D-14415 Potsdam, Germany. E-mail: fanselow@uni-potsdam.de.

2. In the present paper, we focus on the interaction of subject and object wh-phrases. The results reported in Fanselow and Féry (2007) suggest that genuine superiority effects do not arise in the interaction of two object wh-phrases either.

3. The quantificational domain of wer is in fact normally further restricted to humans.

4. The percentage is related to the set of sentences in the NEGRA corpus which begin with a noun phrase and exclude certain occurrences of pronouns (see Weber and Müller 2004).

Note that multiple questions involve two indefinite NPs. Such sentences are underrepresented among OVS sentences ( $4.5 \%$ of the OVS sentences involve two indefinite NPs, while 
$10.4 \%$ of the SVO sentence have two indefinites in the NEGRA corpus, see Weber and Müller (2004)). Given the 81.6:18.4 ratio between SVO and OVS structures in NEGRA, this means that only $9 \%$ of all transitive sentences with an indefinite subject and an indefinite object are object-initial. The superiority condition can thus at most be responsible for the difference between the $9 \%$ OVS structures expected for sentences with two indefinite arguments and the $4.6 \%$ observed in the case of who-what-questions.

5. The multiple questions were constructed on the basis of ditransitive sentences in which the two wh-phrases were drawn from the set \{wer 'who.NOM', was 'what.ACC', wem 'who.DAT', welches $N$ 'which.ACC N', welchem $N$ 'which.DAT N', wann 'when'\}. All 13 grammatically possible combinations were used, in both orders, which accounts for 26 experimental conditions.

6. In the interest of readability, the technical details of our experiments are described in the appendix. The main body of the article reports their results only. Here, it may suffice to say that they all follow the standard design of psycholinguistic experiments (repeated measures both in terms of participants and items per experimental condition).

7. Locative PPs can follow direct objects in normal order in German (Lenerz 1977). The distance between the in situ wh-phrase and the end of the clause (rightmost focus position) is thus identical both in subject-and object-initial conditions. Note that locative adjuncts do not necessarily need stress in the final position.

8. In fact, an inverted six-point rating scale was used in our early experiments (including Experiment 1) We later replaced it with the 7-point scale. The values reported above are not the "raw" values from the six-point scale, but they are mapped from the "real" ones to the sevenpoint scale in order to increase the comparability with the other experiments reported in this paper. The statistical analysis was, however, conducted with the original values.

9. We report this subexperiment in order to give a complete description of Experiment 1. However, the issue that it addresses (viz. how wh-pronouns and which-phrases interact) goes beyond the scope of the present paper.

10. Experiment 2 may also bear on the proposal (Haider 2004; Müller 2004) that the contrast between English and German concerning superiority be explained by the assumption that German subjects may remain in vP, while English subjects must move to Spec,TP. This predicts that superiority effects are confined to subjects in Spec,TP. If Diesing (1992) is correct, the placement of denn in (7) forces a structural analysis in which the subject is not situated in Spec,TP. Nevertheless, crossing movement is inacceptable. However, as one of the anonymous reviewers points out correctly, firm conclusions could be drawn only if the acceptability of (7a) and (7b) is also compared with the ratings of sentences in which denn follows the in situ wh-phrase.

11. There was no animacy related modulation of the crossing effect in Russian (Meyer 2004: 243), but his findings differ from the results reported in Fedorenko and Gibson (submitted) in this respect.

12. The related filler items were multiple questions with two which-phrases.

13. As was noted for Experiment 1, the values reported here have been transformed from the values on the six-point scale actually used in the experiment.

14. We are obliged to Frank Kügler for his help with the acoustic stimuli.

15. This is true only for unmodified wh-pronouns.

16. The data from 4 participants did not enter the analysis because of the too large number of timeouts ( 2 participants) and because they had a rejection rate of 100 percent for one or more of the conditions.

17. Mean response latencies for accepted sentences were $548 \mathrm{~ms}$ (subject initial, animate object), $580 \mathrm{~ms}$ (subject initial, inanimate object), $661 \mathrm{~ms}$ (inanimate object in $1^{\text {st }}$ position), and 884 $\mathrm{ms}$ (animate object in $1^{\text {st }}$ position). The statistical analysis revealed a main effect of word 
order $\left(\mathrm{F}_{1}(1,19)=12.155, \mathrm{p}<.01 ; \mathrm{F}_{2}(1,31)=15.175, \mathrm{p}<.01\right)$ due to higher latencies in the OS sentences. There was a main effect of the animacy of the object in the item analysis only $\left(\mathrm{F}_{1}(1,19)=4.5902, \mathrm{p}<.05 ; \mathrm{F} 2(1,31)=5.7368, \mathrm{p}<.05\right)$. We also found an interaction between both factors $\left(\mathrm{F}_{1}(1,19)=21.104, \mathrm{p}<.001 ; \mathrm{F}_{2}(1,31)=7.5089, \mathrm{p}<.05\right)$. Resolving it revealed higher latencies in object $>$ subject sentences compared to subject $>$ object for animate objects $\left(\mathrm{F}_{1}(1,19)=16.978, \mathrm{p}<.001 ; \mathrm{F}_{2}(1,31)=16.581, \mathrm{p}<.01\right)$, but only as a tendency for the AI pattern $\left(\mathrm{F}_{1}(1,19)=3.1981, \mathrm{p}=.09 ; \mathrm{F}_{2}(1,31)=3.4201, \mathrm{p}=.1069\right)$. The reaction time results thus parallel the findings for the rejections.

18. The absence of a contrast in Experiment 5 is mirrored by a further result gained in the context of Experiment 4. The participants of the experiment also saw 8 items for each of the two structures exemplified in (i), viz. multiple questions with an inanimate nominative DP and an animate object linked to a psychological predicate.

(i) a. Was hat wen beim Vortrag gelangweilt? what has who.ACC at-the talk bored

b. Wen hat was beim Vortrag gelangweilt?

'who was bored by what during the talk?'

Nominative-initial sentences were accepted in $92.9 \%$ of the cases, for accusative-initial sentences acceptance was at $93.6 \%$. There was thus no difference between these two conditions $\left(\mathrm{F}_{1}<1, \mathrm{~F}_{2}<1\right)$, which suggests once more that no crossing effects arise when the two whphrases come from different semantic domains.

19. Unlike what we found in Experiment 1, the animacy agreement effect was insignificant for which-subjects in the inanimate case. This is in line with the general observation that crossing effects are weaker for which-phrases (see Pesetsky 1987, Pesetsky 2000, among others), but we have no explanation for the additional effect of animacy visible here. Likewise, multiple questions with which-subjects were generally rated as more acceptable than sentences with was-subjects. An explanation for this effect is also beyond the scope of the present paper.

20. A quick Google-based internet survey (with the search strings wen hat jede( $r$ ) 'who.ACC has every ...' vs. was hat jede(n) 'what has every ...', Feb 22 2007, 12:20 pm CET) was in line with Experiment 7. There were 16 hits for the former search string. The most remarkable property of these 16 hits is that they all come from syntax papers (all of them were considered grammatical by the respective authors). Things are quite different with (17b). Google found 215 examples. Among the first 100 hits, there was only a single example from a linguistics papers. Even when one carefully eliminates all examples in which was is not the direct object (and not a question pronoun), in which hat is not an auxiliary, and in which jeder is not the pronominal 'everybody' but the determiner 'every', there remain at least 36 hits exactly mirroring (17b). among the first 100 hits. We are well aware of the problems of Google-based results, but we still find the categorial differences between was and wen crossing a univeral quantifier remarkable and quite reminiscent of the representation of multiple questions in the COSMAS corpus.

21. Two questions arise. Our reasoning does not affect the basic difference between a language with (English) and without (German) strict superiority effects, but the sorting key potentials of (19) and its English counterparts should be the same. It would be interesting to see whether there is a pertinent acceptability difference in English, too.

Identical which phrases should be unable to induce sorting key differences, so crossing movement should neither be licensed in English nor in German, unlcss speakers can accomodate a difference between two different sets of girls in (i).

(i) Which girls did which girls invite? 
22. Since this study is not a standard rating experiment, we refrained from subjecting the data to a statistical analysis of variance.

23. In a further informal study, we asked linguists (by an ad in LinguistList) to rate a set of 32 multiple questions posted in the internet (www.ling.uni-potsdam.de/fogra3/neu), of which 4 were simple transitive sentences with wer-wen- and wer-was-pairs, in both orders. 24 native German linguists responded. 5 of them accepted all 4 items, 14 considered the two objectinitial items as worse than their subject-initial counterparts, 4 showed the animacy effect (was-wer was judged as better than wen-wer) and 1 participant rated wen-wer as better than was-wer. Given the differences in methods, these figures cannot be compared easily with our judgment experiments, but if anything they suggest that linguists are more restrictive in their judgments than "normal" speakers of the language.

\section{References}

Arnon, Inbal, Bruno Estigarribia, Philip Hofmeister, T. Florian Jaeger, Jeanette Pettibone, Ivan A. Sag \& Neal Snider. 2005. Rethinking superiority effects - A processing account. Poster presented at the 18th Annual CUNY Conference on Human Sentence Processing, University of Arizona.

Bader, Markus, \& Jana Häussler. 2010. Toward a model of grammaticality judgments. Journal of Linguistics 46. 273-330.

Bolinger, Dwight. 1978. Asking more than one thing at a time. In Henry Hiz (ed.), Questions. 107-150. Dordrecht: Reidel.

Chomsky, Noam. 1973. Conditions on transformations. In Stephen Anderson \& Paul Kiparsky (eds.), A Festschrift for Morris Halle, 232-286. New York: Academic Press.

Chomsky, Noam. 2005. On phases. Unpublished ms. MIT.

Clifton, Charles, Gisbert Fanselow \& Lyn Frazier. 2006. Amnestying superiority violations: Processing multiple questions. Linguistic Inquiry 37. 51-68.

Comorovski, Ileana. 1996. Interrogative phrases and the syntax-semantics interface. Dordrecht: Kluwer.

Comrie, Bernard. 1989. Linguistic typology and linguistic universals. 2nd edn. Chicago: University of Chicago Press.

Cowart, Wayne. 1997. Experimental syntax. Thousand Oaks, CA: Sage.

Diesing, Molly. 1992. Indefinites. Cambridge, MA: MIT Press.

Fanselow, Gisbert. 1991. Minimale Syntax. Groninger Arbeiten zur Germanistischen Linguistik. Groningen.

Fanselow, Gisbert. 2004. The MLC and derivational economy. In Arthur Stepanov, Gisbert Fanselow \& Ralf Vogel (eds.). The minimal link condition, 73-124. Berlin \& New York: Mouton de Gruyter.

Fanselow, Gisbert \& Caroline Féry. 2008. Missing superiority effects: Long movement in German (and other languages). In Jacek Witkós \& Gisbert Fanselow (eds.). Elements of Slavic and Germanic grammars: A comparative view: Papers on topical issues in syntax and morphosyntax, 68-87. Frankfurt: Lang.

Fanselow, Gisbert, \& Stefan Frisch. 2006. Effects of processing difficulty on judgments of acceptability. In Gisbert Fanselow, Caroline Féry, Ralf Vogel \& Matthias Schlesewsky (eds.), Gradience in grammar, 291-316. Oxford: Oxford University Press.

Fanselow, Gisbert, Denisa Lenertovà \& Thomas Weskott. 2008. Studies on the acceptability of object movement to Spec,CP. In Anita Steube (ed.) The discourse potential of underspecified structures, 413-437. Berlin \& New York: Mouton de Gruyter.

Featherston, Sam. 2005. Universals and grammaticality. Linguistics 43. 667-711. 
Fedorenko, Evelina \& Edward Gibson. 2010. Adding a third wh-phrase does not increase the acceptability of object-initial multiple-wh-questions. Syntax 13. 183-195.

Fedorenko, Evelina \& Edward Gibson. Under revision. Syntactic parallelism as an account of superiority effects: Empirical investigations in English and Russian. http://tedlab.mit.edu/tedlab_ website/researchpapers/Fedorenko\%20\&\%20Gibson\%20Superiority\%20subm.pdf

Grewendorf, Günther. 1988. Aspekte der deutschen Syntax. Tübingen: Narr.

Haider, Hubert. 1981. Empty Categories. On some differences between English and German. Wiener Linguistische Gazette 25:13-36.

Haider, Hubert. 1986. Deutsche Syntax - generativ. Vienna: University of Vienna habilitation thesis.

Haider, Hubert. 1997. Economy in syntax is projective economy. In Chris Wilder, Hans-Martin Gärtner \& Manfred Bierwisch (eds.), The role of economy principles in linguistic theory, 205226. Berlin: Akademie Verlag.

Haider, Hubert. 2000. Towards a superior account of superiority. In Uli Lutz, Gereon Müller \& Arnim von Stechow (eds.). Wh scope marking, 231-248. Amsterdam \& Philadelphia: Benjamins.

Haider, Hubert. 2004. The superiority conspiracy. In Arthur Stepanov, Gisbert Fanselow \& Ralf Vogel (eds.). The minimal link condition, 147-175. Berlin: Mouton de Gruyter.

Haider, Hubert \& Inger Rosengren. 2003. Scrambling: nontriggered chain formation in OV languages. Journal of Germanic Linguistics 15. 203-267.

Haupt, Friederike, Matthias Schlesewsky, Dietmar Röhm, Angela Friederici \& Ina BornkesselSchlesewsky. 2008. The status of subject object reanalyses in the language comprehension architecture. Journal of Memory and Language 59. 54-96.

Ishihara, Shinichiro. 2005. Prosody-scope match and mismatch in Tokyo Japanese wh-questions English Linguistics 22. 347-379.

Keller, Frank. 2000. Gradience in grammar: Experimental and computational aspects of degrees of grammaticality. Edinburgh: University of Edinburgh doctoral dissertation.

Kitagawa, Yoshihisa \& Janet D. Fodor. 2006. Prosodic influences on syntactic judgments. In Gisbert Fanselow, Caroline Féry, Ralf Vogel \& Matthias Schlesewsky (eds.). Gradience in grammar, 336-238. Oxford: Oxford University Press.

Lenerz, Jürgen. 1977. Zur Abfolge nominaler Satzglieder im Deutschen. Tübingen: Narr.

Meyer, Roland. 2004. Syntax der Ergänzungsfrage. Munich: Sagner.

Müller, Gereon. 1995. A-bar syntax. A study of movement types. Berlin \& New York: Mouton de Gruyter.

Müller, Gereon. 2004. Phase impenetrability and wh-intervention. In Arthur Stepanov, Gisbert Fanselow \& Ralf Vogel (eds.). The minimal link condition, 289-325. Berlin \& New York: Mouton de Gruyter.

Noonan, Máire. 1988. Superiority effects: How do antecedent government, lexical government and V/2 interact?. McGill Working Papers in Linguistics 6(1). 192-214.

Pesetsky, David. 1987. Wh-in-situ: movement and unselective binding. In Eric Reuland \& Alice ter Meulen (eds.), The representation of (in)definiteness, 98-129. Cambridge, MA: MIT Press.

Pesetsky, David. 2000. Phrasal movement and its kin. Cambridge, MA: MIT Press.

Reinhart, Tanya. 1995. Interface strategies. OTS Working Papers in Linguistics. Utrecht: University of Utrecht.

Sauermann, Antje. 2006. Wortstellung und Diskursprominenz: Eine Korpusstudie. Unpublished diploma thesis. Potsdam: University of Potsdam.

Schlesewsky, Matthias \& Ina Bornkessel. 2004. On incremental interpretation. Lingua 114. 12131234.

Schlesewsky, Matthias \& Ina Bornkessel-Schlesewsky. 2009. The role of prominence information in the real-time comprehension of transitive constructions: A cross-linguistic approach. Language and Linguistics Compass 3(1). 19-58. 
Schütze, Carson. 1996. The empirical base of linguistics: Grammaticality judgments and linguistic methodology. Chicago: University of Chicago Press.

Weber, Andrea \& Karin Müller. 2004. Word order variation in German main clauses: A corpus analysis. Proceedings of the 5th International Workshop on Linguistically Interpreted Corpora (LINC-04), Geneva Switzerland. http//:www.aclweb.org/anthology/W/W04/W04-1911.pdf(accessed 16 March 2011)

Weskott, Thomas \& Gisbert Fanselow. 2008. Variance and informativity in different measures of linguistic acceptability. In Natasha Abner \& Jason Bishop (eds.): Proceedings of the 27th West Coast Conference on Formal Linguistics (WCCFL), 431-439. Somerville, MA: Cascadilla Press.

Weskott, Thomas \& Gisbert Fanselow. 2009. Scaling issues in the measurement of linguistic acceptability. In Sam Featherston \& Susanne Winkler (eds.) The fruits of empirical linguistics, vol. 1: Process, 229-245. Berlin \& New York: Mouton de Gruyter.

Weskott, Thomas \& Gisbert Fanselow. to appear. On the informativity of different measures of linguistic acceptability. Language 87(2).

Wiltschko, Martina. 1998. Superiority in German. In Emily Curtis, James Lyle \& Gabriel Webster (eds.) Proceedings of the Sixteenth West Coast Conference on Formal Linguistics, 431-445. Stanford, CA: CSLI. 